\title{
The caesarean section rate is rising
}

\section{Caesarean section has a case fatality rate 5 to 6 times that of vaginal delivery, in addition to significant long term consequences for the woman}

The caesarean section (CS) rate is rising in Sri Lanka. In government hospitals the rate increased from $9 \%$ in 1986 to $14.4 \%$ in $1999(1,2)$. It is highest in the maternity hospitals $(25.8 \%)$, followed by teaching hospitals $(23.5 \%)$ and provincial hospitals (21\%) (2). In one teaching hospital the CS rate was 42\% in 1999 (2). Another tertiary care unit reports an increase in the CS rate from $13 \%$ in 1985 to $22 \%$ in 1999 (3). The rise in CS rate is a world-wide phenomenon. In 1999 the CS rate in UK and USA were 20\% and $22 \%$ respectively $(4,5)$. CS is a time-honoured approach to shorten or avoid labour when the woman, the child, or both are in danger, but carries significant long term consequences for women of childbearing age.

The four main indications for CS in a tertiary care unit in Sri Lanka during 1985-86 and 1999 are shown in the Table. In addition to severe pre-eclampsia and failed induction emerging as important indications in 1999, 5\% of the CS were for breech presentation (3). The increase in CS rate may not be due to any change in the indications but to a reduction in the threshold for doing a CS (6). The decision to perform a CS is often made on the basis of a telephone conversation between a junior doctor and the specialist. A study from a teaching hospital shows that specialist participation in the decision to perform a CS took place in only $37.5 \%$ of cases (7). Lack of acceptable indications for the procedure was observed in many instances. Another study has shown that the majority of women having CS had no part in the decision making process (8).

Many reasons for the high rates of CS in developed countries are also relevant to Sri Lanka. Limitation of family size and the couple's expectation of a healthy child at the end of each pregnancy has put pressure on obstetricians. Fear of malpractice litigation and "defensive medicine" may have a major impact on the increased CS rate. Complacency regarding the safety of CS has influenced practice habits and clinical judgement. Where there is doubt. CS appears to be the answer. Young obstetricians' lack of experience in performing operative vaginal deliveries may also contribute to the increase in CS rates. Increased use of epidural anaesthesia and fetal monitoring, which has a high false positive rate in the detection of fetal hypoxia and acidosis, are also probable reasons for the increase in CS rate. Financial gain for the obstetrician has been suggested as an explanation. New indications have also contributed to CS rate increase. CS on demand is a new phenomenon encountered by obstetricians (9). Elective CS are now performed to protect the pelvic floor from obstetric trauma and its consequences such as genital prolapse, and urinary and anal incontinence (10).

\author{
Table. Indications for CS in a tertiary \\ care unit in Sri Lanka (3)
}

$\begin{array}{lcc}\text { Indication } & \begin{array}{c}\text { Incidence in } \\ \text { I985-86(\%) }\end{array} & \begin{array}{c}\text { Incidence in } \\ 1999(\%)\end{array} \\ \text { Previous CS } & 30 & 32 \\ \text { Fetal distress } & 21 & 13 \\ \begin{array}{l}\text { Failure of } \\ \text { progress of labour }\end{array} & 5 & 9 \\ \text { Failed induction } & 5 & 8\end{array}$

\section{Risks}

Although the risks of CS have decreased over the years, morbidity and mortality remain much higher after abdominal than after vaginal delivery. The case fatality rate for all CS is 5 to 6 times that for vaginal delivery. Even an elective CS carries a 2.8-fold higher chance of the woman's death than if she had a vaginal delivery (II, 12). Post-operative risks include haemorrhage, infection, ileus, pulmonary embolism and Mendelson's syndrome. Hysterectomy for haemorrhage after CS is 10 times that after vaginal delivery (13). Long term morbidity includes formation of adhesions, intestinal obstruction, bladder injury and uterine rupture during subsequent pregnancy. There is evidence suggesting decreased fecundity, increased risk of ectopic pregnancy, placenta praevia, placenta accreta and worsened infant outcome in subsequent pregnancies (14). Feelings of inadequacy, guilt and failure in not completing a natural process may effect bonding between mother and infant, particularly if the CS was done under general anaesthesia. Several studies have documented an association between emergency CS and subsequent psychological problems, especially postnatal depression $(15,16)$.

The benefits of an emergency CS performed for a fetal indication during labour will outweigh the risks to the baby of not doing it. Where the baby is not in trouble, the risks to the baby still exist. The first is the chance that the surgeon's knife will accidentally lacerate the fetus (6\% with non-vertex presentations) (17). Inadvertent prematurity is another possibility. CS in itself is a potent risk factor for respiratory distress syndrome in preterm infants and for 
other forms of respiratory distress in term infants (18). Mechanical ventilation to treat presumed surfactant deficiency is 120 times more likely to be needed after elective CS delivery at less than 37 to 38 weeks, than after delivery at 39 to 41 weeks (19). In addition, for term infants, CS before the onset of labour results in a greater risk of neonatal respiratory morbidity than delivery by other means.

\section{Benefits}

An increase in the CS rate alone does not improve the perinatal outcome (20). Improved socioeconomic status of the population together with advances in neonatal care facilities contribute a great deal to improving perinatal outcome. The benefits include prevention of potential hazards of vaginal delivery and genital trauma, which can lead to utero-vaginal prolapse, stress incontinence, and faecal incontinence. It could be argued that elective CS is convenient to the patient, her family, and the hospital staff. Emergency CS carries a higher morbidity and mortality rate compared to elective CS $(11,12)$.

\section{Cost}

The increase in CS rate is associated with an increase in cost of health care. In the UK it is estimated that each percentage increase in CS rate costs the National Health Service one million Sterling pounds (4). Estimates of the cost of one CS vary from 24 to 780 Sterling pounds $(21,22)$.

\section{The ideal CS rate}

The World Health Organisation (WHO) set an optimal rate of 10 to $15 \%$ for CS in 1985 (23). There was no evidence that higher CS rates lowered maternal mortality rates. Last year, the task force on CS rate of the American College of Obstetricians and Gynaecologists recommended a target for reducing the CS rate to $15 \%$ in the USA by the year 2010 (24).

To suggest that one CS rate is good for all populations in all countries seems an authoritarian approach to health care delivery. It implies that women should have no say in their own care. The risks and benefits clearly need to be discussed with patients, but it is important to distinguish between informed maternal choice and maternal choice persuaded by clinicians.

Women who need a CS should be able to have one under optimum conditions. Clearly, in Sri Lanka this is not the case. In 1999, of the 90 specialist obstetricians and gynaecologists in government hospitals, 22 were based in the Colombo district where only $18 \%$ of births take place. Four districts had none. Of the 52 anaesthetists, 24 were based in Colombo. Twelve districts had none. (2). Hence there is a need to ensure a more equitable distribution of trained staff, particularly of the specialist grade.

\section{Measures to reduce the $\mathrm{CS}$ rate}

The CS rate can be lowered by reducing the rate of first CS and by increasing the rate of trial of labour with a view to vaginal delivery after a previous CS. The most common indication for a first CS is dystocia. Using oxytocin judiciously in the first and second stages of labour can reduce the CS rate. Failed induction is a consequence of unnecessary intervention. When there is a valid indication to deliver the baby, but the cervix is unfavourable for induction, in Sri Lanka CS is the only recourse. Unfortunately, because of the fear that prostaglandins and their analogues may be misused to perform abortions, they are not available for cervical ripening and induction of labour in Sri Lanka.

A non-engaged head at term in a primigravida or in a woman with a previous CS should not be considered in itself as cephalo-pelvic disproportion (CPD). It should not be considered an indication for elective CS unless the diagnosis of CPD is obvious.

External cephalic version (ECV) at term will reduce the incidence of CS in breech presentation though it is more likely to be successful in multigravidae. There is genera) agreement that a planned CS is better than a planned vaginal delivery for the baby in breech presentations at term if the presentation is footling, if there is fetal distress, a large baby, or a congenital abnormality that could cause a mechanical problem at vaginal delivery. Recently, the Term Breech Trial has shown that a policy of planned CS is substantially better for a singleton fetus in a breech presentation at term (25). However, these findings could reflect the deterioration or lack of skills in carrying out an assisted breech delivery by obstetricians of today. In properly selected cases a forceps or vacuum delivery can significantly reduce both maternal and fetal morbidity and mortality without resorting to CS.

A trial of labour in women who have had a previous CS leads to vaginal delivery in 60 to $92 \%$ of instances. Recent studies have shown that a trial of scar is safe and a vaginal delivery can be achieved even after two previous CS in carefully selected cases (26). Although most women and their obstetricians would not be happy to take the risk, this evidence justifies a trial of scar in selected patients who have had only one previous CS. The major risk of a trial of labour is that the uterus may rupture during labour and result in haemorrhage requiring hysterectomy. The risk of uterine rupture is approximately $1 \%$ (27). On the other hand, maternal morbidity and length of hospital stay is significantly higher with CS. In addition, respiratory morbidity is significantly greater in babies delivered by elective repeat CS than those born by trial of labour (28). If the trial of labour fails, the repeat CS in performed on a woman who has been in labour for some time with ruptured membranes, conditions that increase maternal morbidity. Compared with infants delivered by elective repeat CS, those delivered by CS after a trial of labour have significantly increased rates of a suspected and proven sepsis.

\section{Should we reduce the CS rate?}

The quality of care given to the woman and baby should not be compromised by unplanned attempts at reducing the CS rate. However, appropriate measures should be adopted to minimise the risks of anaesthesia and surgery. 
The reported nationl rate of CS for 1999 may not appear excessive, but when one looks at the individual hospital figures a different picture emerges. In some areas there is a very high rate of CS, whereas in others it is low. It seems relevant to redistribute anaesthetic and obstetric specialist resources to enhance the use of operative delivery to improve perinatal and maternal outcome.

\section{CS on demand}

There is increasing support for a woman's right to choose an elective CS rather than await spontaneous labour and vaginal delivery even when there is no contraindication for vaginal delivery (9). Ethically, the patients' right to refuse or limit therapy is well recognised. If a woman has the right to decide the modality of treatment in non-life threatening situations (eg. contraception, menorrhagia), why not the right to decide on the mode of delivery? Has she the right to request a CS? If elective CS is justified for high risk pregnancies, is it justified to undergo the risks of labour in normal pregnancies, and in moderate risk pregnancies eg. breech presentation, occipito-posterior position, twins, previous CS due to a non-recurrent condition where the scar is reasonably sure? Elective CS should not be considered unnatural in as much as medications are not considered unnatural. A study in Italy has found that only $4 \%$ of healthy women with normal pregnancies requested elective CS (29). In 1998,38\% of all elective CS done in one district hospital in the UK were at the request of women who had no contraindication for vaginal delivery (30).

The increased risks of morbidity and mortality of CS should always be considered. The obstetrican should not become merely a technician carrying out wishes of patients. The woman should be fully informed of all the risks and allowed to accept one set of risks or the other, but the lay public should not be led to believe that CS is the best, and that labour and vaginal delivery are not so good.

\section{Conclusions}

Attempts should be made to reduce unnecessary CS by doing it only when it is obstetrically justified, especially in primigravidae. An experienced obstetrician should be directly involved in the diagnosis and management of labour. They should be skilled in the art of obstetric manipulations. Participation of specialists in the decision to perform CS is essential if the rate is to be reduced. A more equitable distribution of obstetricians is also clearly important to achieve this.

Careful selection of patients for induction of labour, allowing a trial of scar in selected patients, and ECV at term for breech presentation are interventions that would reduce CS rate. The patient should be fully informed and advised on the risks and benefits of elective CS or anticipated vaginal delivery, and should participate in decision making together with the obstetrician.

\section{References}

1. Fernando L, Abeywardena M. Trends in caesarean section. Sri Lanka Journal of Obstetrics and Gynaecology 1992-1993; 16: $14-20$.
2. Annual Health Bulletin. Department of Health Services, Sri Lanka, 1999.

3. Gunarathna KA, Goonewardene IMR. The rise in caesarean section rates. Sri Lanka Journal of Obstetrics and Gynaecology 2001: (in press).

4. Commentary. Caesarean section is on the rise. Lancet 2000; 356: $1997-8$.

5. Ferriman A. Caesarean section rate hits $20 \%$ in 1999-2000. British Medical Journal 2001: 322: 1508-10.

6. Leitch CR, Walker JJ. The rise in caesarean section rate: the same indications, but a lower threshold? British Journal of Ostetrics and Gynaecology 1998; 105: 621-6.

7. Sirisena J, Jiffrey N. Preventability of caesarean operations. Proceedings of the Kandy Society of Medicine 1994; 16: 456. (abstract).

8. Randeniya C. Women's involvement with the decision preceding their caesarean section and their degree of satisfaction. Workshop on presentation of research findings in reproductive health, 1997.

9. Patterson-Brown S. Elective caesarean section - a woman's right to choose? In: Progress in Obstetrics and Gynaecology. JStudd, Ed. 2000; 14: 202-15.

10. Sultan A H, Stanton S L. Preserving the pelvic floor and perineum during childbirth by elective caesarean section. British Journal of Obstetrics and Gynaecology 1996; 174: 192-6.

11. Lilford RJ, Van Coeverden de Groot HA, Moore PJ, Bingham $\mathrm{P}$. The relative risks of caesarean section (intrapartum and elective) and vaginal delivery; a detailed analysis to exclude the effects of medical disorders and other acute preexisting physiological disturbances. British Journal of Obstetrics and Gynaecology 1990; 97: 883-92.

12. Hall MH, Bewley S. Maternal mortality and mode of delivery. Lancet 1999; 254: 776-9.

13. Amu O, Rajendran S, Bolaji II. Maternal choice alone should not determine method of delivery. British Medical Journal 1998; 317: 463-5.

14. Hemminki E, Merilainen J. Long term effects of caesarean section: ectopic pregnancies and placental problems. American Journal of Obstetrics and Gynaecology 1996; 174: 1569-74.

15. Boyce PM, Todd AL. Increased risk of postnatal depression after emergency caesarean section. Medical Journal of Australia. 1992; 157: 172-4.

16. Fisher J, Astbury J, Smith A. Adverse psychological impact of operative obstetric interventions: a prospective longitudinal study. Australia New Zealand Journal of Psychiatry 1997; 31: 728-38.

17. Smith JF, Hernandez C, Wax JR. Fetal laceration injury at cesarean section delivery. Obstetrics and Gynaecology 1997; 90:344-6.

18. Rubaltelli FF, Bonafe L, Tangucci M, Spagnolo A, Dani C. Italian Group of Neonatal Pneumonology. Epidemiology of neonatal acute respiratory disorders. Biology of the Neonate 1998; 74: 7-15. 
19. MadarJ, Richmonds S, Hey E. Hyaline membrane disease after elective delivery at term. Acta Paediatrica 1999; 88: 1244-84.

20. Sanchez-Ramos L, Kaunitz AM, Peterson HB, Martinez Schnell B, Thompson RJ. Reducing caeserean section at a teaching hospital. American Journal of Obstetrics and Gynaecology. 1990; 163: 1081-87.

21. Audit commission. First class delivery; improving maternity services in England and Wales. Abingdon; Audit commission publications, 1997.

22. MacKenzie IZ. Should women who elect to have caesarean section pay for them? British Medical Journal 1999; 318: 1070.

23. World Health Organization. Appropriate technology for birth. Lancet 1985 ; 2 : 456-7.

24. Task force on caesarean delivery rates of the American College of Obstetricians and Gynaecologists. Valuation of Caesarean delivery. Washington DC, 2000.
25. Hannah ME, Hannah WJ, Hewson SA, Hodnett ED, Saigal S, Willan AR. Term Breech Trial Collaborative Group. Lancet 2000; 356: 1375-83.

26. Jamelle RN. Outcome of unplanned vaginal deliveries after two previous caesarean sections. Journal of Obstetrics and Gynecological Research. 1996; 22: 431-6.

27. Flamm BL, Goings JR, Liu Y, Wolde-Tsadik G. Elective repeat caesarean delivery versus trial of labour: a prospective multicenter study. Obstetrics and Gynaecology 1994; 83: 927-32.

28. Hook B, Kiwi R, Amini SB, Fanoroff A, Hack M Neonatal morbidity after elective repeat Caesarean section and trial of labour. Paediatrics 1997; 100: 348-53.

29. Rosen MG, Dickinson JC, Westhoff CL. Vaginal birth after caesarean: a metanalysis of morbidity and mortality. Obstetrics and Gynaecology 1991; 77: 465-70.

30. Jackson NV, Irvine LM. the influence of maternal request on the elective caesarean section rate. Journal of Obstetrics and Gynaecology. 1998; 18: 115-9.

P C Gunasekera, Specialist, Reproductive Health Services, UNFPA Country Technical Services Support Team, South and West Asia, Kathmandu, Nepal. P S Wijesinghe, Senior Lecturer, Department of Obstetrics and Gynaecology, Faculty of Medicine, University ofKelaniya, Ragama. I M R Goonewardene, Associate Professor and Head, Department of Obstetrics and Gynaecology, Faculty of Medicine, University of Ruhuna, Galle. (Accepted 21 July 2001. The views expressed in this article are those of the authors and are not necessarily those of the respective institutions). 